\title{
The Effects of Spirituality and Religiosity on Well-Being of People With Cancer: A Literature Review on Current Evidences
}

\author{
Zeinab Ahmadi ${ }^{1}$; Fatemeh Darabzadeh ${ }^{2}$; Morteza Nasiri ${ }^{1,4}$; Miad Askari ${ }^{3}$ \\ ${ }_{1}^{1}$ Department of Nursing, Nursing and Midwifery School, Ahvaz Jundishapur University of Medical Sciences, Ahvaz, IR Iran \\ ${ }_{2}^{2}$ Department of Nursing, Nursing and Midwifery School, Shahid Beheshti University of Medical Sciences, Tehran, IR Iran \\ 3 Department of Health Care Management, Health School, Ahvaz Jundishapur University of Medical Sciences, Ahvaz, IR Iran \\ ${ }^{*}$ Corresponding author: Morteza Nasiri, Department of Nursing, Nursing and Midwifery School, Ahvaz Jundishapur University of Medical Sciences, Ahvaz, IR Iran. Tel: +98-9171745485, \\ Fax:+98-7726225292, E-mail: mortezanasiri.or87@yahoo.com
}

Received: August 16, 2014; Revised: January 25, 2015; Accepted: February 20, 2015

\begin{abstract}
Context: Receiving a diagnosis of cancer can be devastating and life-altering news for any person. Recent studies have shown that spirituality and religiosity may have positive effects on physical and psychological well-being in patients with cancer. This review article aimed to assess the effects of spirituality and religiosity on well-being of patients with cancer.

Evidence Acquisition: A literature search was done for related articles published between 2000 and 2014 on PubMed, Science Direct, Embase, Web of Science, and Scopus for both English and non-English language articles by the following keywords: "cancer", "spirituality", "religion/religious/religiosity", and "Well-being".

Results: Of the 16 studies reviewed, ten studies have found that spirituality and religiosity were positively associated with well-being, two studies found no association, and four studies showed both beneficial and detrimental effects of spirituality and religiosity on well-being of patients with cancer.

Conclusions: Most of the reviewed articles showed the important role of religiosity and spirituality in palliative treatment of patients with cancer. It has recommended that medical care team, especially nurses, pay more attention to spiritual and religious beliefs of patients with cancer to improve their well-being.
\end{abstract}

Keywords: Cancer; Spirituality; Religiosity; Well-Being; Literature Review

\section{Context}

Cancer is one of the rapidly growing diseases that involves about 12 million people worldwide (1). It is reported that seven million patients die of cancer annually, and 25 million people are currently living with a diagnosis of cancer (2). In developed countries, cancer has become the leading cause of death, and in developing countries, it is second only to heart diseases (3). Based on World Health Organization (WHO) report, the increasing cancer burden affirms the urgent need for prevention and care $(2,4)$. Today, palliative care is considered as the key goal for patients living with cancer $(5,6)$. The WHO defines palliative care as an approach that improves the quality of life (QoL) of patients and their families facing life-threatening diseases by means of prevention or early identification and treatment of patients, which could be physical, psychosocial, or spiritual (7). This holistic approach recognized that the needs of dying patients were complex and multifaceted and, therefore, required going beyond a conventional biomedical understanding of the disease and its treatment (8). Based on literature, spirituality and religiosity are two essential subjects in palliative care that have attracted an increasing interest among patients with can- cer in the context of health and healthcare practice (6, 9). The National Quality Forum (NQF) identifies spiritual and religious aspects of care as one of eight domains of quality palliative and hospice care in patients with cancer (10). Moreover, WHO definition of palliative care has cited that spiritual and religious aspects of care are essential to good palliative care among patients with cancer (7). According to the National Cancer Institute, spirituality is defined as "an individual's sense of peace, purpose, and connection to others, and beliefs about the meaning of life" that may be expressed through religion or other means, while religiosity, one type of expression of spirituality, is defined as "a set of beliefs and practices associated with a particular religious tradition or denomination" (11). Today, the role of spirituality and religiosity in the adjustment to cancer has been studied in both qualitative (12-18) and quantitative (19-34) studies. It is recognized that the spirituality and religiosity as a holistic human characteristic can have a positive influence on improvement of patients' QoL (9, $25,26,31,34-36)$, functional well-being (37), and physical well-being (38) and reduce of distress symptoms (33, 38, 39 ) in patients with cancer. It is reported that between

Copyright (C) 2015, Ahvaz Jundishapur University of Medical Sciences. This is an open-access article distributed under the terms of the Creative Commons Attribution-NonCommercial 4.0 International License (http://creativecommons.org/licenses/by-nc/4.0/) which permits copy and redistribute the material just in noncommercial usages, provided the original work is properly cited. 
$50 \%$ and $95 \%$ of patients with cancer view religion and spirituality as personally important issues $(40,41)$. Patients with cancer report their spirituality helps them find hope, gratitude, and positivity in their cancer experience, and that their spirituality is a source of strength that helps them cope, find meaning in their lives, and make sense of the cancer experience as they recover from treatment (42). These two variables also serve multiple functions in long-term adjustment to cancer such as maintaining self-esteem, providing a sense of meaning and purpose, and giving emotional comfort (43). Despite the important role of religious and spiritual beliefs in the lives of patients with cancer, these two variables can also adversely affect patients with cancer' health (44). Some investigations have found that spiritual and religious experiences and practices cause depression, poorer QoL, and callousness towards others if they saw the crisis as a punishment from God, if they feel excessive guilt, or if they had an absolute belief in prayer and cure and an inability to resolve their anger if cure did not occur $(42,45)$.

Due to the contradictory results of previous research regarding to the effect of spirituality and religiosity on well-being of people with cancer, and considering that most studies conducted in this regard are qualitative, we decided to review quantitative studies that assessed the effects of spirituality and religiosity on well-being of people with cancer.

\section{Evidence Acquisition}

In this review article, we performed an electronic search on articles published from August 1, 2000 through April 28, 2014, on PubMed, Science Direct, Embase, Web of Science, and Scopus for both English and non-English language articles, using the following keywords as medical subject heading (MeSH): "cancer", "spirituality", "religion/religious/religiosity", and "Well-being”. The references of retrieved items were also searched to identify additional items about this topic. In addition, reference lists of journal papers were searched by hand for relevant papers. We included articles that examined the role of spirituality and religiosity in patients aged $\geq 18$ years with a diagnosis of cancer within the last five years. We excluded studies that examined spirituality and religiosity in children with cancer, in relatives of patients with cancer, or in professionals and caregivers. Moreover, we excluded quantitative and review studies.

In total, we found 1032 items (including duplication). After careful reading of title, abstract, and full text (when available), 110 articles were initially selected, but after further reading, 40 studies that met the eligibility criteria were included. We excluded 24 of these 40 articles due to lack of patient history (14 articles), being quantitative and review studies (8 articles), being done in children (2 articles). Therefore, 16 studies were finally included in this review.

\section{Results}

Among 16 evaluated studies, 12 studies were cross-sectional (19-22, 24-26, 29, 31-34), three were longitudinal $(23,27,28)$, and one was randomized clinical trial (RCT) (47) in design. Based on results, eight were conducted in the United States $(20,21,24,25,27-29,31)$, two in Canada $(19,32)$, two in Iran $(34,46)$, two in Taiwan $(32,33)$, one in Australia (22), and one in both Korea and the United States (26). Most patients were English speaking with a Christian or Jewish religion. Sample sizes of studies ranged from 32 to 198. Ages of the participants ranged from 19 to 84 years. Seven studies examined mixed cancer groups $(20,25,26,31)$. Of the 12 studies that examined specific types or sites of cancers, the majority examined breast cancer $(19,21,23,24,27-29,34)$. Of the 16 reviewed studies, ten studies $(19,22,23,26,28,29,31,33,34,46)$ have found that spirituality and religiosity were positively associated with well-being, two $(21,27)$ found no association, and four $(20,24,25,32)$ showed both beneficial and detrimental effects of spirituality and religiosity on wellbeing of patients with cancer (Table 1).

Table 1. Studies Exploring the Effects of Spirituality and Religiosity on Well-Being of People With Cancer ${ }^{\text {a }}$

\begin{tabular}{|c|c|c|c|c|}
\hline Reference, Country & Study Aims & $\begin{array}{c}\text { Study } \\
\text { Design }\end{array}$ & $\begin{array}{c}\text { Sample Size and Cancer } \\
\text { Site }\end{array}$ & Findings \\
\hline $\begin{array}{l}\text { Gall et al. 2000, } \\
\text { Canada (19) }\end{array}$ & $\begin{array}{l}\text { To explore religious resources in } \\
\text { long-term adjustment to } \mathrm{BC}\end{array}$ & $\begin{array}{c}\text { Cross- } \\
\text { sectional }\end{array}$ & $\begin{array}{l}32 \text { patients with BC } \\
\text { diagnosed in past } 5 \text { years } \\
\text { recruited from newspaper } \\
\text { and BC-specific newsletter }\end{array}$ & $\begin{array}{l}\text { Relationship with God or God image as a religious } \\
\text { resource, and religious coping behavior were related to } \\
\text { the survivors' well-being. An image of God as benevolent } \\
\text { was strongly correlated with a lack of psychological dis- } \\
\text { tress }(\mathrm{r}=0.51, \mathrm{P}<0.008) \text {. A strong correlation was found } \\
\text { between religious discontent as a coping mechanism } \\
\text { and diminished life satisfaction }(\mathrm{r}=0.66, \mathrm{P}<0.008) \text {. }\end{array}$ \\
\hline $\begin{array}{l}\text { Nairn and Merluzzi, } \\
2003, \text { USA }(20)\end{array}$ & $\begin{array}{l}\text { To determine whether three } \\
\text { types of religious coping } \\
\text { strategies are related to QoL and } \\
\text { adjustment to cancer }\end{array}$ & $\begin{array}{l}\text { Cross- } \\
\text { sectional }\end{array}$ & $\begin{array}{l}192 \text { patients with different } \\
\text { kinds of cancer }(\mathrm{n}=154 \text { for } \\
\text { illness adjustment and } \mathrm{n}= \\
\quad 138 \text { for QoL) }\end{array}$ & $\begin{array}{l}\text { Religious coping (deferring collaborative) showed a } \\
\text { positive association with illness adjustment }(\mathrm{P}<0.05) \\
\text { but no association with QoL. }\end{array}$ \\
\hline $\begin{array}{l}\text { Manning-Walsh, } \\
\text { 2005, USA (21) }\end{array}$ & $\begin{array}{l}\text { To examine association between } \\
\text { symptoms distress and QoL } \\
\text { when religious support and per- } \\
\text { sonal support were introduced }\end{array}$ & $\begin{array}{l}\text { Cross- } \\
\text { sectional }\end{array}$ & $\begin{array}{l}100 \text { women with BC aged } \\
\text { from } 46 \text { to } 52 \text { years }\end{array}$ & $\begin{array}{l}\text { Personal support was positively correlated with QoL } \\
\text { and partially mediated the effects of symptom distress. } \\
\text { Religious support did not mediate symptom distress } \\
\text { and was not directly related to QoL. }\end{array}$ \\
\hline
\end{tabular}


Ahmadi Z et al.

\begin{tabular}{|c|c|}
\hline $\begin{array}{l}\text { Boscaglia et al.2005, } \\
\text { Australia (22) }\end{array}$ & $\begin{array}{c}\text { To determine whether spiritual } \\
\text { involvement and beliefs and } \\
\text { positive and negative spiritual } \\
\text { coping could account for any } \\
\text { of the variation in anxiety and } \\
\text { depression }\end{array}$ \\
\hline $\begin{array}{l}\text { Wildes et al. 2009, } \\
\text { USA (25) }\end{array}$ & $\begin{array}{l}\text { To assess association between } \\
\text { religion (practices and beliefs) } \\
\text { and spirituality (social support } \\
\text { from spiritual community) and } \\
\text { health-related QoL }\end{array}$ \\
\hline
\end{tabular}

Purnell et al.2009, To investigate the association USA (24) between religious practice and spirituality and QoL and stress in survivors of BC

Lim and Yi, 2009, osity, spirituality, and social support on QOL of Korean-American and Korean BC and GC survivors Hebert et al.2009, To explore the association be-
USA (27) being in patients with cancer

$\begin{array}{cc}\begin{array}{c}\text { Cross- } \\ \text { sectional }\end{array} & \begin{array}{c}100 \text { women within one-year } \\ \text { diagnosis of GC }\end{array} \\ \begin{array}{c}\text { Cross- } \\ \text { sectional }\end{array} & \begin{array}{c}117 \text { cancer survivors from } \\ \text { clinics, organizations, and } \\ \text { support group }\end{array} \\ & \text { sup }\end{array}$

Crosssectional

130 women with stage II or III BC that assessed after two years of diagnosis

\section{Cross- 161 women diagnosed with} sectional BC and GC (110 Koreans and 51 Korean-Americans
Younger women, who used more negative spiritual copng, had a greater tendency towards depression and that the use of negative spiritual coping was associated with greater anxiety scores. Although not statistically significant, patients with lower levels of generalized spirituality also tended to be more depressed

Modest significant correlations were found between religion and spirituality with health-related QoL subscales include social well-being $(\mathrm{r}=0.27, \mathrm{P}<0.005)$ and functional well-being $(r=0.216, P=0.022)$. However, significant association were not found between religion/spirituality and emotional well-being and physical well-being

A hierarchical regression analysis showed a strong positive association between spiritual well-being and $\mathrm{OoL}(\mathrm{B}=$ $0.65, \mathrm{P}<0.001)$ and an inverse association between spiritual well-being and stress $(\mathrm{B}=-0.39, \mathrm{P}<0.001)$. Whereas religious practice was not significantly associated with these variables.

Religiosity and spirituality were associated with some QOL outcomes in different patterns in Korean-American

Longitudinal 198 women with stage I or II and 86 women with stage IV BC

Negative religious coping (ie, feeling abandoned by or anger at God) predicted worse overall mental health and life satisfaction ( $2 \%$ of the variance). Positive religious coping (ie, partnering with God or looking to God for strength, support, or guidance) was not associated with any measures of well-being

Gall et al.2009, Canada (23)

To investigates the association between religious coping and emotional distress and emotional well-being at each point in time across the process of adjustment for $\mathrm{BC}$

Longitudinal

93 patients with $\mathrm{BC}$ and 160 women with a benign diagnosis

Women who worked with God or choose to surrender to God reported higher emotional well-being and lower emotional distress at various points from pre-diagnosis period through 2-year postsurgery $(\mathrm{r} 2=0.28 ; \mathrm{P}<0.02$ or greater). Women who pleaded for direct intercession from God reported higher emotional well-being pre-surgically $(\mathrm{r} 2=0.25, \mathrm{P}<0.006)$ and higher emotional distress one week postsurgery $(\mathrm{r} 2=0.21, \mathrm{P}<0.015)$

$\begin{array}{lccc}\begin{array}{l}\text { Friedman et al. 2010, } \\ \text { USA (29) }\end{array} & \begin{array}{c}\text { To examine association between } \\ \text { self-blame, self-forgiveness, } \\ \text { spirituality, mood, and QOL for } \\ \text { having developed BC }\end{array} & \begin{array}{c}\text { Cross- } \\ \text { sectional }\end{array} & 108 \text { with early BC } \\ \begin{array}{l}\text { Bussell and Naus, } \\ \text { 2010, USA (28) }\end{array} & \begin{array}{c}\text { To investigate coping responses } \\ \text { during chemotherapy and how } \\ \text { these coping responses during } \\ \text { chemotherapy and at two year }\end{array} & \begin{array}{c}\text { Longitudinal } \\ \text { fhem }\end{array} & \begin{array}{c}59 \text { patients with BC during } \\ \text { chemotherapy (Time 1), and } \\ \text { 24 patients two years later }\end{array} \\ \text { (Time 2) }\end{array}$

Greater levels of spirituality and self-forgiveness were associated with decreased mood disturbance and better $\mathrm{QOL}(\mathrm{P}<0.01)$

Using religion at time of chemotherapy $(\mathrm{r}=0.42, \mathrm{P}<$ $0.04)$, and 2 years following chemotherapy $(r=0.56, P$ $<0.04$ ) were associated with post-traumatic growth (as a proxy for psychologic well-being) 2 years following chemotherapy and assess patients' perception of spiritual care in the cancer care setting

Au et al. 2012, Taiwan (32)

To examine the association between spirituality and indicators of sexuality (eg, self-concept,

satisfaction, function) and

health-seeking behaviors

\section{Li et al. 2012, Taiwan To examine association between (33) \\ Moeini et al. 2014, Iran (46) demographic and clinical char- acteristics, spiritual well-being and psychosocial adjustment \\ Cross- sectional \\ To determine the effects of a supportive presence and support for religious rituals on anxiety of patients with leukemia}

$\begin{array}{lcc}\text { Jafari et al. 2013, } & \begin{array}{c}\text { To investigate the association of } \\ \text { QOL with spirituality }\end{array} & \begin{array}{c}\text { Cross- } \\ \text { sectional }\end{array}\end{array} \quad$ 68 patients with BC
cancer and underw colostomy surgery group)
Cross- 69 patients with advanced sectional cancer receiving palliative radiation therapy

Patient spirituality and religious coping were associated with improved QOL in multivariable analyses $(\beta=10.57$, $\mathrm{P}$ $<0.001$ and $\beta=1.28, P=0.01$, respectively). Most patients considered attention to spiritual concerns an important part of cancer care by physicians (87\%) and nurses (85\%)

$\begin{array}{cc}\text { Cross- } & 120 \text { adults with rectal } \\ \text { sectional } & \text { cancer }\end{array}$

Spirituality was positively and significantly correlated with better communication ( $\mathrm{r}=0.47, \mathrm{P}<0.001)$, resourcefulness $(r=0.32, P=0.000)$, sexual relationship $(r=0.48$ $\mathrm{P}<0.001)$, male sexual self-concept $(\mathrm{r}=0.44, \mathrm{P}=0.000)$ and female sexual self-concept $(r=0.47, P=0.007)$. However, spirituality was not associated with sexual function in men or women

45 Taiwanese patients aged Spiritual well-being was significantly associated with psy42 to 83 years who were chosocial adjustment $(\mathrm{r}=-0.52, \mathrm{P}<0.01)$, and 4 predictors diagnosed with colorectal (income change after surgery, self-rated disease severity, time since surgery, and spiritual well-being) accounted for $53 \%$ of the variance in psychosocial adjustment

64 adult patients with leukemia $(\mathrm{n}=32$ in each

There was no significant difference between the two groups before the intervention. However, after the intervention, mean score of anxiety were significantly lower in the experiment group than in the control group $(\mathrm{P}<$ 0.01). There was also a significant difference in the scores of the experiment group before and after the intervention $(\mathrm{P}<0.01)$

There was a significant positive correlation between general QoL and total spiritual well-being scores $(r=0.59$, $\mathrm{P}<0.001)$

\footnotetext{
a Abbreviations: BC, breast cancer; GC, gynecologic cancer; and QoL, quality of life.
} 


\section{Conclusions}

In this review, we have summarized studies that assessed the effects of spirituality and religiosity on wellbeing of patients with cancer. Although reviewed studies vary in terms of methodology, kinds of cancer, and objectives, results consistently show the importance of religiosity and spirituality in coping with a cancer diagnosis and subsequent treatment. Based on evidences, most review studies that investigated the effects of religiosity and spirituality in patients with cancer showed mixed results. Thune-Boyle et al. (47) reviewed 17 studies examining religious and spiritual cognitions and/or behaviors as coping strategies in adults dealing with cancer. They found only seven of 17 studies with some evidence for the beneficial effect of religious coping, but one of these also found religious coping to be detrimental in a sub-sample of their population. Three studies found religious coping to be harmful, and seven did not find significant results. In another review study that was conducted by Visser et al. the majority of the cross-sectional studies (31 of 36) found a positive association between spirituality and well-being and four studies with a longitudinal design showed mixed results (48). Moreover, a recent systematic review confirmed that spirituality and religiosity were associated with reduced mortality only in studies on healthy populations, but not in studies on diseased population (49). However, there are some review studies that indicated the association of religiosity and spirituality with better well-being in patients with cancer. In a review, Schreiber et al. (50) suggested that religion and/or spirituality can play a role in maintaining and/or increasing well-being among breast cancer survivors. Moreover, in an integrative review of the current literature, Tate provides support that spirituality is a meaningful part of the breast cancer experience for African-American women, and has important role for patients to overcome the physical, psychological, and emotional burdens that accompany a breast cancer diagnosis (51).

The discrepancy in the findings may result from using insensitive measures of religiosity and spirituality, relying on cross-sectional designs, or failing to incorporate cultural diversity in measures and designs. Today, various mechanisms are identified to be implicated in the relation between religiosity and spirituality and outcomes of cancer treatment. Results of recent studies have shown that cancer survivors have adjusted to their life-threatening illnesses by holding onto hope, compensating for losses, and actively maintaining their personal lives through a process of experiential learning. This learning process allowed individuals to create or discover opportunities that might lead to maintaining or gaining some enjoyment of life even as suffering continue during the course of their cancer and recovery $(52,53)$.

In addition, studies suggested that spirituality and religiosity with such mechanisms include behavioral, physical, social support, and psychologic buffering of the sever- ity of cancer symptoms. Behavioral mechanisms include religious encouragement (i.e. the religion encourages the adoption of a set of behavioral practices) to engage in various health behaviors such as offering diet guidelines (e.g. diets low in fat or to avoid nicotine). Physiologic mechanisms include participating in religious practices (e.g. prayer and meditation) offering means of relaxation and thereby contributing to better health outcomes. Socialization is a key element of religious attendance and it increases with increased religious involvement. The benefits of social support are extensively documented in the health psychology literature; however, it also appears that religious and spiritual beliefs provide benefits in their own right because they facilitate increased intimacy and connection with others. Regarding psychological mechanisms, spirituality and religiosity are found to enhance psychologic well-being through lowering levels of depression, anxiety, and hopelessness, and consequently, indirectly affect physical health. Another mechanism is cognitive improvement that has not been extensively investigated as mediator in the association between religious coping and cancer treatment outcome $(38,54)$. Therefore, more research is needed in this area to better understand the specific factors, mechanisms, and pathways of action that mediate religiosity and spirituality in cancer treatment. Despite the beneficial effects of religiosity and spirituality on cancer, these patients are prone to spiritual distress upon facing with their diagnosis, change in disease stage, and the difficulties of ending their lives that may lead to poorer outcomes and is, therefore, considered maladaptive.

Today, the importance of spiritual and religious beliefs in patients with cancer was discussed from numerous perspectives in the nursing literature $(55,56)$. Florence Nightingale noted that spirituality is intrinsic to human nature and is our deepest and most potent resource for healing in patients with cancer (57). In a recent study conducted by Winkelman et al. on terminally ill patients with cancer, most patients (87\%) agreed it was important for nurses to consider patients' spiritual concerns within the medical setting (36). However, it is reported in many studies that religious and spiritual needs of advanced patients with cancer are not supported by nurses $(9,58$, $59)$. Based on studies, $81 \%$ of patients with cancer reported that most nurses ignored their spiritual or religious beliefs (59), and $72 \%$ reported their spiritual needs were supported minimally or not at all by nurses (9). The main reason for this negligence may be the lack of healthcare professional training, design of clinical practices, shortages of healthcare providers, payment, and policy constraints. Therefore, to provide holistic nursing care, nurses must understand that spirituality and religiosity are important in most patients with cancer. It is recommended that nurses assess the role of spirituality and religiosity in patients with cancer and develop personalized plans 
of care as they accompany these patients throughout the cancer journey. Totally, spiritual and religious beliefs are not a static and often changes as the cancer experience unfolds. Therefore, close surveillance of patients is necessary to ensure that cues indicating spiritual and religious needs are not missed. Nurses also should nurture and support their own spirituality and religiosity to be available as a spiritual and religious resource for their clients. Our study had some limitations that should be considered. First, many reviewed studies were cross-sectional in design that make it impossible to establish causality among spirituality, religiosity, and various physical and psychosocial symptoms. Second, the sample sizes of most reviewed articles were relatively small. Third, most studies used mixed cancer groups at different stages of their illness, which could affect their sense of well-being. Fourth, the majority of the studies in this review were conducted in the United States ( 8 of 16). According to the United States Central Intelligence Agency, 81\% of Americans adhere to one of the three major religions (Christianity, Judaism, and Islam), which may differ considerably from other countries. Therefore, in order to fully understand the role of religiosity and spirituality in cancer treatment, future studies should examine these two factors as their main aim, using specific cancer groups that are similar in terms of length of illness. In addition, use of more longitudinal and randomized clinical trials and specific questionnaires are suggested. Furthermore, future studies should consider a systematic control for possible influential variables such as perceived social support.

The most reviewed articles show the importance role of religiosity and spirituality in palliative treatment of patients with cancer, thus, confirming the place of spirituality and religiosity in the holistic construct of palliative care among patients with cancer.

\section{Acknowledgements}

Hereby, we appreciate Mr Habibi, the chief of Workgroup of Science and Religion for technical support.

\section{Authors' Contributions}

Zeinab Ahmadi, Fatemeh Darabzadeh, and Morteza Nasiri contributed equally to this work and performed the literature search and wrote first draft; Morteza Nasiri and Miad Askari provided expert opinion and reviewed the paper.

\section{Funding/Support}

This article was supported by Workgroup of Science and Religion of Ahvaz University of Medical Sciences, Iran.

\section{References}

1. Carter D. New global survey shows an increasing cancer burden. Am J Nurs. 2014;114(3):17.
2. Vineis P, Wild CP. Global cancer patterns: causes and prevention. Lancet. 2014;383(9916):549-57.

3. Popat K, McQueen K, Feeley TW. The global burden of cancer. Best Pract Res Clin Anaesthesiol. 2013;27(4):399-408.

4. Nyatanga B. Supporting patients in coping with cancer. Br J Community Nurs. 2014;19(5):255.

5. Rocque GB, Cleary JF. Palliative care reduces morbidity and mortality in cancer. Nat Rev Clin Oncol. 2013;10(2):80-9.

6. Ireland J. Palliative care: a case study and reflections on some spiritual issues. Br J Nurs. 2010;19(4):237-40.

7. World Health Organization.. Cancer Palliative care is an essential part of cancer control.: WHO; 2014. Available from: http://www. who.int/cancer/palliative/en/.

8. Cobb M, Dowrick C, Lloyd-Williams M. What can we learn about the spiritual needs of palliative care patients from the research literature? J Pain Symptom Manage. 2012;43(6):1105-19.

9. Balboni TA, Vanderwerker LC, Block SD, Paulk ME, Lathan CS, Peteet JR, et al. Religiousness and spiritual support among advanced cancer patients and associations with end-of-life treatment preferences and quality of life. J Clin Oncol. 2007; 25(5):555-60.

10. National Consensus Project for Quality Palliative Care.. Clinica Practice Guidelines for Quality Palliative Care.: National Consensus Project; 2009. Available from: http://www.nationalconsensusproject.org/guideline.pdf.

11. National Cancer Institute at the National Institutes of Health.. Spirituality in Cancer Care. 2009. Available from: http://www. cancer.gov/cancertopics/pdq/supportivecare/spirituality/Patient/page1.

12. Alcorn SR, Balboni MJ, Prigerson HG, Reynolds A, Phelps AC, Wright AA, et al. "If God wanted me yesterday, I wouldn't be here today": religious and spiritual themes in patients' experiences of advanced cancer. J Palliat Med. 2010;13(5):581-8.

13. Harper FW, Nevedal A, Eggly S, Francis C, Schwartz K, Albrecht TL. "It's up to you and God": understanding health behavior change in older African American survivors of colorectal cancer. Transl Behav Med. 2013;3(1):94-103.

14. Harandy TF, Ghofranipour F, Montazeri A, Anoosheh M, Bazargan M, Mohammadi E, et al. Muslim breast cancer survivor spirituality: coping strategy or health seeking behavior hindrance? Health Care Women Int. 2010;31(1):88-98.

15. Lepherd L. Spirituality in men with advanced prostate cancer: "it's a holistic thing . . . it's a package". J Holist Nurs. 2014; 32(2):89-101.

16. Smith AR, DeSanto-Madeya S, Perez JE, Tracey EF, DeCristofaro S, Norris RL, et al. How women with advanced cancer pray: a report from two focus groups. Oncol Nurs Forum. 2012;39(3):E310-6.

17. Ahmad F, Muhammad M, Abdullah AA. Religion and spirituality in coping with advanced breast cancer: perspectives from Malaysian Muslim women. J Relig Health. 2011;50(1):36-45.

18. Sabado M, Tanjasiri SP, Alii SM, Hanneman M. Role of Spirituality in Coping with Breast Cancer: A Qualitative Study of Samoan Breast Cancer Survivors and their Supporters. Calif J Health Promot. 2010;8(SE):11-22.

19. Gall TL, Miguez de Renart RM, Boonstra B. Religious resources in long-term adjustment to breast cancer. J Psychosoc Oncol. 2000;18(2):21-37.

20. Nairn RC, Merluzzi TV. The role of religious coping in adjustment to cancer. Psychooncology. 2003;12(5):428-41.

21. Manning-Walsh J. Social support as a mediator between symptom distress and quality of life in women with breast cancer. $J$ Obstet Gynecol Neonatal Nurs. 2005;34(4):482-93.

22. Boscaglia N, Clarke DM, Jobling TW, Quinn MA. The contribution of spirituality and spiritual coping to anxiety and depression in women with a recent diagnosis of gynecological cancer. Int J Gynecol Cancer. 2005;15(5):755-61.

23. Gall TL, Guirguis-Younger M, Charbonneau C, Florack P. The trajectory of religious coping across time in response to the diagnosis of breast cancer. Psychooncology. 2009;18(11):1165-78.

24. Purnell JQ, Andersen BL, Wilmot JP. Religious Practice and Spirituality in the Psychological Adjustment of Survivors of Breast Cancer. Couns Values. 2009;53(3):165. 
25. Wildes KA, Miller AR, de Majors SS, Ramirez AG. The religiosity spirituality of Latina breast cancer survivors and influence on health-related quality of life. Psychooncology. 2009;18(8):831-40.

26. Lim JW, Yi J. The effects of religiosity, spirituality, and social support on quality of life: a comparison between Korean American and Korean breast and gynecologic cancer survivors. Oncol Nurs Forum. 2009;36(6):699-708.

27. Hebert R, Zdaniuk B, Schulz R, Scheier M. Positive and negative religious coping and well-being in women with breast cancer. $J$ Palliat Med. 2009;12(6):537-45.

28. Bussell VA, Naus MJ. A longitudinal investigation of coping and posttraumatic growth in breast cancer survivors. J Psychosoc Oncol. 2010;28(1):61-78.

29. Friedman LC, Barber CR, Chang J, Tham YL, Kalidas M, Rimawi MF, et al. Self-blame, self-forgiveness, and spirituality in breast cancer survivors in a public sector setting. J Cancer Educ 2010;25(3):343-8.

30. Schreiber JA. Image of God: effect on coping and psychospiritual outcomes in early breast cancer survivors. Oncol Nurs Forum. 2011;38(3):293-301.

31. Vallurupalli M, Lauderdale K, Balboni MJ, Phelps AC, Block SD, Ng $\mathrm{AK}$, et al. The role of spirituality and religious coping in the quality of life of patients with advanced cancer receiving palliative radiation therapy.J Support Oncol. 2012;10(2):81-7.

32. Au TY, Zauszniewski JA, King TM. Health-seeking behaviors and sexuality in rectal cancer survivors in Taiwan: associations with spirituality and resourcefulness. Oncol Nurs Forum. 2012;39(5):E390-7.

33. Li CC, Rew L, Hwang SL. The relationship between spiritual wellbeing and psychosocial adjustment in Taiwanese patients with colorectal cancer and a colostomy. J Wound Ostomy Continence Nurs. 2012;39(2):161-9.

34. Jafari N, Farajzadegan Z, Zamani A, Bahrami F, Emami H, Loghmani A. Spiritual well-being and quality of life in Iranian women with breast cancer undergoing radiation therapy. Support Care Cancer. 2013;21(5):1219-25.

35. Fisch MJ, Titzer ML, Kristeller JL, Shen J, Loehrer PJ, Jung SH, et al. Assessment of quality of life in outpatients with advanced cancer: the accuracy of clinician estimations and the relevance of spiritual well-being--a Hoosier Oncology Group Study. J Clin Oncol. 2003;21(14):2754-9.

36. Winkelman WD, Lauderdale K, Balboni MJ, Phelps AC, Peteet JR, Block SD, et al. The relationship of spiritual concerns to the quality of life of advanced cancer patients: preliminary findings. $J$ Palliat Med. 2011;14(9):1022-8.

37. Shahmoradi N, Kandiah M, Loh SP. Quality of life and functional status in patients with advanced cancer admitted to hospice home care in Malaysia: a cross-sectional study. Eur J Cancer Care (Engl). 2012;21(5):661-6.

38. Kim Y, Seidlitz L. Spirituality moderates the effect of stress on emotional and physical adjustment. Pers Individ Dif 2002;32(8):1377-90.

39. Rawdin B, Evans C, Rabow MW. The relationships among hope, pain, psychological distress, and spiritual well-being in oncology outpatients. J Palliat Med. 2013;16(2):167-72.

40. True G, Phipps EJ, Braitman LE, Harralson T, Harris D, Tester W. Treatment preferences and advance care planning at end of life: the role of ethnicity and spiritual coping in cancer patients. Ann
Behav Med. 2005:30(2):174-9.

41. Gall TL, Cornblat MW. Breast cancer survivors give voice: a qualitative analysis of spiritual factors in long-term adjustment. Psychooncology. 2002;11(6):524-35.

42. Puchalski CM. Spirituality in the cancer trajectory. Ann Oncol. 2012;23 Suppl 3:49-55.

43. Thune-Boyle IC, Stygall J, Keshtgar MR, Davidson TI, Newman SP. Religious/spiritual coping resources and their relationship with adjustment in patients newly diagnosed with breast cancer in the UK. Psychooncology. 2013;22(3):646-58.

44. Mueller PS, Plevak DJ, Rummans TA. Religious involvement, spirituality, and medicine: implications for clinical practice. Mayo Clin Proc. 2001;76(12):1225-35.

45. Puchalski CM. Religion, medicine and spirituality: what we know, what we don't know and what we do. Asian Pac J Cancer Prev. 2010;11 Suppl 1:45-9.

46. Moeini M, Taleghani F, Mehrabi T, Musarezaie A. Effect of a spiritual care program on levels of anxiety in patients with leukemia. Iran J Nurs Midwifery Res. 2014;19(1):88-93.

47. Thune-Boyle IC, Stygall JA, Keshtgar MR, Newman SP. Do religious/spiritual coping strategies affect illness adjustment in patients with cancer? A systematic review of the literature. Soc Sci Med. 2006;63(1):151-64.

48. Visser A, Garssen B, Vingerhoets A. Spirituality and well-being in cancer patients: a review. Psychooncology. 2010;19(6):565-72.

49. Chida Y, Steptoe A, Powell LH. Religiosity/spirituality and mortality. A systematic quantitative review. Psychother Psychosom. 2009;78(2):81-90.

50. Schreiber JA, Brockopp DY. Twenty-five years later--what do we know about religion/spirituality and psychological well-being among breast cancer survivors? A systematic review. J Cancer Surviv. 2012;6(1):82-94.

51. Tate JD. The role of spirituality in the breast cancer experiences of African American women. J Holist Nurs. 2011;29(4):249-55.

52. Mystakidou K, Tsilika E, Parpa E, Pathiaki M, Patiraki E, Galanos A, et al. Exploring the relationships between depression, hopelessness, cognitive status, pain, and spirituality in patients with advanced cancer. Arch Psychiatr Nurs. 2007;21(3):150-61.

53. Edmondson D, Park CL, Blank TO, Fenster JR, Mills MA. Deconstructing spiritual well-being: existential well-being and HRQOL in cancer survivors. Psychooncology. 2008;17(2):161-9.

54. Karekla M, Constantinou M. Religious coping and cancer: Proposing an acceptance and commitment therapy approach. Cogn Behav Pract. 2010;17(4):371-81.

55. Strang S, Strang P, Ternestedt BM. Spiritual needs as defined by Swedish nursing staff. JClin Nurs. 2002;11(1):48-57.

56. Granero-Molina J, Diaz Cortes MM, Marquez Membrive J, CastroSanchez AM, Lopez Entrambasaguas OM, Fernandez-Sola C. Religious faith in coping with terminal cancer: what is the nursing experience? EurJCancer Care (Engl). 2014;23(3):300-9.

57. Widerquist JG. The spirituality of Florence Nightingale. Nurs Res 1992;41(1):49-55.

58. Best M, Butow P, Olver I. Spiritual support of cancer patients and the role of the doctor. Support Care Cancer. 2014;22(5):1333-9.

59. Astrow AB, Wexler A, Texeira K, He MK, Sulmasy DP. Is failure to meet spiritual needs associated with cancer patients' perceptions of quality of care and their satisfaction with care? J Clin Oncol. 2007;25(36):5753-7. 